\title{
DYSPHASIA IN LEFT-HANDED PATIENTS WITH UNILATERAL BRAIN LESIONS
}

\author{
BY \\ M. E. HUMPHREY and O. L. ZANGWILL \\ From the Department of Neurology, Radcliffe Infirmary, and the Institute of Experimental Psychology, Oxford
}

The importance of the left cerebral hemisphere for speech and allied functions in right-handed persons is an accredited fact, whatever may be its correct explanation. In the same way it has commonly been assumed that in the case of lefthanded persons the same importance attaches to the right hemisphere. Thus unequivocal handedness, whether right or left, has been thought to imply a corresponding "dominance" of the hemisphere contralateral to the preferred hand.

Evidence concerning the cerebral organization of left-handed people has inevitably been scarce. One of the earliest cases on record is that reported by Hughlings Jackson (1879), of motor aphasia associated with left-sided hemiplegia in a railway signalman whose speech was restricted to the single recurring utterance, "Come on to me !" ; the patient was said to be left-handed. Later Head (1926) reported a case of semantic aphasia in a man who had always been strongly left-handed, " even using a chopper with the left hand"; here again the lesion was right-sided. Exceptional cases have been reported from time to time in which aphasia was associated with a lesion of the hemisphere ipsilateral to the individual's preferred . hand. Bramwell (1899) suggested that in most of these cases, which he termed " crossed " aphasia, enquiry will reveal first that the patient's ancestors were all right-handed, and secondly that the patient himself has been taught to write with the right hand and/or is ambidextrous. Crossed aphasia as a transitory phenomenon is not uncommon, and was in Bramwell's view due to the fact that in certain individuals corresponding areas of the minor hemisphere play a definite, if subordinate, part in speech, so that injury to such areas gives rise to mild and transient dysphasic symptoms. Persistent crossed aphasia, on the other hand, was in Bramwell's experience confined to left-handers, except where there was reason to suppose that the normal development of the speech centres had been interfered with in early life. It may be added that the present writers have searched the literature in vain for a convincing case of crossed aphasia in an overtly right-handed person.

The problem of ambidexterity and mixed hand dominance has seldom been considered from this point of view. Some writers have suggested that bilateral cortical representation of speech functions is to be expected in ambidextrous cases, as also in young children before unequivocal hand dominance has been finally established. Gowers (quoted by McNaughton-Jones, 1914), in his plea for the cultivation of ambidexterity, put forward the view that " as far as can be judged from present facts, by the use of both hands equally for all manual occupations, including writing, we should secure immunity from grave defects of speech" (i.e., if disease of either hemisphere were to occur). Such a view appears to have been founded on somewhat dubious theoretical considerations rather than on clinical and pathological evidence, which at that time was virtually non-existent. Admittedly Bastian (1898) had reported the case of an ambidextrous marine engineer who developed complete motor aphasia in association with right-sided hemiplegia. The patient continued to write fluently with his left hand, and before his illness had been able to use both hands equally well. Speech recovered suddenly 24 days after the onset of the attack. However, while doubtless the early literature of aphasia contains a few other unusual cases of this type, it is only comparatively recently that systematic study of the laterality of brain lesions causing aphasia in relation to handedness has been attempted. Thus Weisenburg and McBride (1935) found that among 92 cases of unequivocal handedness there were only four exceptions to the rule that aphasia results from a lesion of the dominant hemisphere as indicated by handedness, and fails to result from a lesion of the minor hemisphere ; in other words, the inference from handedness to cerebral dominance was justified in about $95 \%$ of their cases. Of their five ambidextrous cases, three 
developed aphasia from a left-sided lesion and one from a right-sided lesion.

Chesher (1936) summarized the evidence from 166 cases of circumscribed lesion within the speech area of one or other cerebral hemisphere. He found that where a patient was strictly unilateral in his hand dominance, be it right or left, hemisphere dominance followed the normal rule. (There were, however, only three purely left-handed patients in his series.) Where on the other hand a naturally left-handed patient had been taught to write with the right hand, thus acquiring a measure of ambidexterity in some cases and a mixture of hand preferences in others, aphasia appeared with lesions of either hemisphere. In all there were nine such cases : all showed aphasic symptoms, the lesion being left-sided in five cases, right-sided in four. In regard to this atypical group Chesher suggested that "the tentative conclusion is justified that their language mechanism is unlateralized, so that a lesion on either side is capable of producing a disturbance of speech".

Needles (1942) quoted four cases in which the common factors were loss of function of the right hand, adoption of function by the left hand, and onset of aphasia at a much later date. The lesion giving rise to the aphasia was left-sided in two cases and right-sided in the other two. He adopted Chesher's hypothesis of bilateral cortical representation of speech in explanation of these cases, while at the same time suggesting that in naturally left-handed persons training of the right hand, for example, in writing, may result in the left hemisphere acquiring dominance for speech. An account by Tilney (1936) of the circumstances of his own aphasia is of interest in this connexion.

Conrad (1949) studied 47 cases of traumatic brain lesion in markedly left-handed patients. Of these 18 showed some form of speech disturbance, the lesion being left-sided in 10 cases, right-sided in seven, and bilateral in the one remaining case. Severe and lasting dysphasic syndromes were observed in five cases of left-sided and the same number of right-sided injuries; other left-handed cases showed only slight and transitory dysphasia where the nature of the injury was such as would have been expected to cause a more profound loss of speech. Thus left-handedness, in Conrad's view, differs from right-handedness in that it does not imply strict dominance of the contralateral hemisphere, but on the contrary shows all the signs of less advanced specialization.

In view of the limitations and inconclusiveness of the evidence produced by previous writers, it was felt that any fresh cases bearing on the problem of cerebral dominance should be placed on record. The authors were fortunate in having access to the detailed histories of approximately 1,150 cases of penetrating brain wounds from the recent world war. These were studied from the viewpoint of psychological functions in general, but especially with reference to handedness and the different effects of left- and right-sided cerebral lesions. In what follows we shall be concerned primarily with the various manifestations of dysphasia, although other symptoms will be noted as and when they are considered relevant.

\section{Selection of Cases}

Despite the large total of cases surveyed, the necessary information did not prove to be available in a sufficient number to enable a statistical study to be made, as was originally planned. (Lefthandedness is, after all, a comparatively rare phenomenon, being confined in its more obvious forms to about 7 to $8 \%$ of the population, according to conservative estimates (Wile, 1934)). The only alternative was to select from the total material cases showing clear evidence of a marked tendency towards left-handedness and to report them in some detail. It was hoped that even a very small number of carefully studied cases might provide useful information concerning the degree of cerebral dominance associated with atypical handedness.

The selection of cases was based on the following criteria. (1) the lesion must be strictly unilateral. (2) The patient must have been tested specifically for dysphasia by adequate methods and at varying intervals. A psychological report based on routine psychometric tests, while clearly desirable, was not considered indispensable. (3) In the absence of dysphasia the lesion must be such as would be expected to interfere with speech functions if the affected hemisphere were the dominant one. (4) Adequate information was required as to the patient being left-handed; mere indications that the patient was not entirely right-handed were considered insufficient. (5) The patient should be of at least average pretraumatic intelligence, in so far as could be judged from his personal history and/or psychological tests. (In the event most of the patients selected were of above average intelligence.) This proviso was made in order to exclude cases of so-called " pathological " left-handedness, as described by Russell Brain (1945).

This method of selection yielded a total of no more than 10 cases, in five of which the lesion was left-sided and in five right-sided. All showed some degree of dysphasia in the early stages of recovery, and all were predominantly left-handed. 
It must be emphasized that, with one or two exceptions, the writers were unable to examine these cases personally, and were thus obliged to rely on the written testimony of other observers and, in some cases, of the patients themselves.

\section{Cases of Left Hemisphere Injury}

The severity of the dysphasic symptoms, both initial and residual, in our selected group of lefthanded patients with left hemisphere injuries shows marked individual variations, as the following brief histories reveal. In only one case, however, was the speech loss so severe as to be permanently disabling.

Case 1 (No. 14718).-A private, aged 36, normally left-handed except for writing, sustained in May, 1944, a severe penetrating wound of the left hemisphere which caused gross destruction of the temporal lobe. No information is available as to his condition in the two years immediately following his injury, but when readmitted in July, 1946, his general physical condition was good. Neurologically he showed a right upper quadrantic field defect, but remarkably little sensorimotor disability. Post-traumatic amnesia was assessed at between three and four weeks. An electroencephalogram showed unusually severe abnormality over a wide area in the left hemisphere. Psychological examination revealed a severe disability in the verbal field with marked impairment of reading and writing and severe dyscalculia. Spontaneous speech was sometimes nearly normal in grammatical form, choice of words, and enunciation, and at other times he managed to convey a good deal of what he wanted to say by drama, or by writing an odd word or figure. He had great difficulty in naming common objects, but expressive speech, reading, and writing were all more impaired than comprehension. He showed marked perseveration, and psychometric tests gave evidence of gross general intellectual loss.

When re-examined in September, 1947, his spontaneous speech showed an increase in vocabulary and he could name $95 \%$ of objects presented, but the socalled "telegraphic" style was still in evidence. Writing had improved but reading remained at the same rudimentary level. In addition, a slight receptive difficulty was suggested by his tendency to answer questions of his own instead of those put by the examiner.

In April, 1949, the patient's speech therapist reported that he was still suffering from a very severe expressive dysphasia, dysgraphia, and dyslexia. There was, however, a considerable improvement in his receptive powers, and he was continuing to make slow but steady progress in both expressive speech and reading. Before the war he had been a shipping clerk, but his disability prevented him from returning to his former occupation, and he was advised instead to take up some form of light manual work.

As regards handedness, the severity of dysphasia made it impossible to obtain a full and accurate accoun:, but it was ascertained that before his injury he had used the right hand for writing and drawing (presumably owing to early training, though this was never established with certainty), but would throw and play tennis left-handed. He was left-footed.

A lesser but well-marked degree of speech impairment was shown by the following patient :-

Case 2 (No. 9616).- An officer, aged 23, naturally left-handed but partially ambidextrous, sustained a penetrating mortar shell wound of the left parietooccipital region in August, 1944. Operation (Lieut. James) revealed that the dura was torn and the brain lacerated. Pulped brain, clot, and three bone chips were sucked out and a metallic foreign body removed. The bone defect, which was in the left mid-parietal area in the inter-auricular line, measured $5 \times 3 \mathrm{~cm}$. Neurologically his main symptom was a right-sided hemiparesis ; there was no hemianopia.

Initially he showed complete motor aphasia, but could understand the spoken word and obey simple commands. Three weeks after injury he was able to say "yes" and "no" and "good morning", but the rest of his speech was slow and laboured and full of mistakes, which, however, he was quick to recognize. He was thus unable to name objects or read aloud but he could write down the names of objects correctly with his left hand and succeeded in writing a letter more or less correctly and without undue difficulty.

Five weeks later (about two months after injury) the word-mutilations had disappeared and he was speaking with what would pass for an ordinary stammer. Psychological examination at that time revealed little evidence of intellectual impairment apart from a slight residual dysphasia ; memory and abstract thought were almost unimpaired, but there was a tendency, probably dysphasic, to make slips, e.g., in letter writing. Pretraumatic intelligence was judged to be well above average.

When re-admitted in December, 1945, his main physical disabilities were the remnants of his right hemiparesis and some sensory abnormalities in the right hand. Speech still showed a slight hesitation and slowness but on the whole had recovered very well. There was an occasional mild paraphasic error, and spelling was slow and a little uncertain. Reading and writing were both apparently normal, but there was some slight impairment in calculation. He had meanwhile been attempting a certain amount of difficult reading (e.g., Trevelyan's English Social History) and had found some difficulty in retaining the knowledge and ideas thus acquired. The more complex material he had to read some six or seven times before being able to memorize it, though comprehension of the meaning of individual sentences was little impaired. Once he had committed something to memory he considered that his powers of retention were as good as ever. He was also aware of a slight impairment of constructive thought, and when writing an essay was apt to lose the thread of the argument. In general, however, he had made a reasonably good recovery from his injury, and his 
intellectual capacity had suffered only at the higher levels of conceptual thinking.

This improvement was subsequently maintained and he was able to manage successfully clerical work of a moderately responsible nature. When interviewed by one of us (M.E.H.) in November, 1950, he could add little to the account so far given. He stated that his memory was now " extraordinarily erratic", especially for names, yet on tests of immediate memory, both verbal and visual, he was easily within normal limits. His subjective feelings of memory impairment became more readily understandable in the light of his statement that at school his capacity for rote learning had been well above average. Certainly he had made an excellent recovery from his early dysphasia, the residual signs of which were obvious only under unfavourable conditions, such as fatigue or emotional stress. In view of his superior abilities it was perhaps too much to expect that he would ever regain full command of his intellectual powers, yet for all practical purposes he was back to normal.

Handedness was of considerable interest in this case. Though naturally left-handed, attempts had been made to convert him to right-handed writing over a period of about eight months, at the age of 8 or 9 . These attempts he had resolutely resisted and he had in fact continued to write with his left hand, though acquiring a certain ambidexterity, especially for games, such as tennis, in which he would transfer the racket from his left to his right hand in order to avoid back-hand shots. In most things, however, he always preferred to use his left hand and regarded himself as primarily left-handed. $\mathrm{He}$ was also left-footed and left-eyed. He did not know of any left-handedness in his immediate family.

That dysphasia may involve a selective amnesia for words without any appreciable degree of general memory disturbance is commonly acknowledged. In the following case, however, where the residual dysphasic handicap was largely confined to a difficulty in word-finding, there was also evidence of a more widespread disorder in the memory sphere.

Case 3 (No. 2671). - A regular officer, aged 44, naturally left-handed, sustained a severe penetrating gunshot wound of the left fronto-temporal area in October, 1940. The bullet entered the left orbit and the point of exit was in the posterior part of the left temporal lobe. There was haematoma of the left orbit, and the left eye was destroyed. Operation (Mr. Summers and Mr. Oliver) was performed on the following day, revealing complete laceration of the orbital structures, and the remains of the left eye were removed. A second operation (Mr. Oliver) was performed a fortnight later, in which small pieces of necrotic bone were removed. The duration of post-traumatic amnesia was estimated as approximately six weeks, and retrograde amnesia as two days.

The patient was at first unconscious, and had a rightsided facial paralysis. Two days after injury he recog- nized his surroundings, and was able to ask for a bottle. Four days later he was reported as occasionally talking rationally, but it was not until three weeks after injury that he began to show any marked improvement in his mental condition. At this time he was described as "quite intelligent, but still aphasic". By the end of November, 1940, (seven to eight weeks after injury) the aphasia had practically cleared up, and his memory was said to be very good except for the names of people and places.

When examined in December, 1940, there was some loss of 2-point discrimination in the right hand but no other abnormal neurological signs, and he was reported to have made a good recovery from a very severe injury. Owing to post-traumatic amnesia he had no memory of the period during which he had been completely aphasic. His main complaint now was of his speech and memory. $\mathrm{He}$ had great difficulty in expressing himself and in recalling the names of objects ; though usually able to produce the correct name eventually, he was occasionally at a loss, e.g., over a pencil-sharpener, where he was obliged to resort to pantomine. Except when tired he could grasp and define the meaning of words, but his reaction to questions was slow, suggesting that oral comprehension was probably a little impaired. Writing was affected to about the same degree as speech ; thus he was at first unable to write a cheque to his satisfaction, could not think of the words he wanted, and when he did attempt to write the result was an illegible scrawl. $\mathrm{He}$ also had great difficulty in spelling even simple words. The following is a specimen of his writing at this stage : "I have a shoot of 2,500 acres, where game are very .... (long pause, and then) aborive (for " abundant"). No shooting has been done. I have been in Palestine, Iraq and Persia, the journey is best by travelling to Kurdistan. However it will be impossible to use your car when it is park then use your mule." Reading on the other hand was relatively easier: a little slow but, except when hurried, fairly accurate. He admitted to some difficulty in concentration and in comprehension of the total meaning, but was sure that he could identify and understand individual words. In addition to his specific loss of memory for words and for the names of acquaintances, there was evidence of a more general memory deficit, in that he was unable to recall recent events, even those after the period of post-traumatic amnesia, and would often forget things he wanted to do.

On his return to duty in May, 1941, (about seven months after injury) he was employed in an administrative capacity. Subjectively both speech and memory continued to improve, but he found himself frequently unable to memorize instructions. Thus he would visit his Commanding Officer, be told to do something, and by the time he had got outside the door he had forgotten what he had to do. This difficulty he overcame to some extent by writing down notes of all his orders. Physically he felt " as fit as hell" ; his main complaint, in fact, was his memory, and in particular he was distressed by his inability to recall the names of racehorses.

When next examined in December of the same year, 
he reported considerable further improvement in both speech and memory. His difficulties remained of much the same character, but he was learning to adjust to them and felt that he could manage his work more adequately. On the other hand a report from his Commanding Officer stated that " his memory cannot be relied upon, and his general behaviour is that of a man who has not entirely recovered from a serious injury". His difficulty in word-finding was still very marked in ordinary conversation, especially when he was searching for some precise expression, for example : "Battleships are no damn good, they're too big, they can't .... . what's the bloody word I want, you can't hide them." Despite this difficulty, or possibly on account of it, he showed a remarkable capacity for making himself understood by circumlocution, gesture, and vocal inflection. His powers of oral comprehension remained appreciably retarded, and he still complained of difficulty in following a rapid conversation. Reading and writing were apparently back to normal, but spelling was still considerably disturbed, e.g., he mis-spelt about one out of every three words from the scholastic age level of 10 upwards (buisness, discease, promiscuse). His behaviour here suggested that he relied very much on the auditory word-image for his spelling. On psychological examination, his dysphasic handicap did not prevent him from obtaining a very superior score (38 plus) on the Stanford-Binet vocabulary test, and he was able to repeat seven digits forwards with an effort. His reproduction of the "cowboy story" was good. On a picture-naming test he scored 32 out of a possible 36 successes, his only obstacles being toy truck, dressingtable, comb, and alarum clock. Simple tests of visual memory revealed no significant impairment. A score of $33 / 60$ on the Raven matrices hinted at some degree of general intellectual deterioration, although it was difficult to determine how much of the test result was due to his impaired efficiency and how much to his temperamental response to the test situation. The general impression was that " the impairment of learning and concentration is comparatively little and probably capable of further improvement; being an extroverted character and a versatile personality, he copes with his word-amnesia rather well and will do better still under conditions where his temperament does not carry him away".

Although he had had a generalized epileptic attack a few months previously, an electroencephalogram showed no evidence of abnormality, and there were no abnormal neurological signs.

Very little information is available as to his subsequent progress. When re-admitted briefly in August, 1949 (nearly nine years after injury), he stated that his general health was still good, and that he had been travelling all over the world. Subjectively his speech was almost normal, although he would occasionally bring out a word the exact opposite of what he had intended.

As regards handedness, this was another case of a naturally left-handed man who had been taught to write with his right hand at an early age. He did not lay any special claim to ambidexterity, and did not know of any left-handedness in his immediate family.

Two further cases of left hemisphere injury in which the dysphasic manifestations were less striking, may be reported more briefly.

Case 4 (No. 9531). -A private, aged 30, showed early global dysphasia with mild right-sided hemiparesis following a deep wound of the left frontal lobe penetrating to the ventricle; there was probably some degree of intellectual deterioration, but he achieved a good physical recovery and appreciable recovery of language functions within six months, although still liable to difficulties of word-finding 18 months after injury.

Case 5 (No. 10213). - A corporal, aged 32, who was naturally left-handed though partially ambidextrous, also presented a similar picture of early global dysphasia, with associated right hemiplegia, following a penetrating wound of the left parietal lobe. Gradual recovery from the hemiplegia took place over the first four months after injury, with similar improvement in language functions.

\section{Cases of Right Hemisphere Injury}

In the group of left-handed patients with right hemisphere injuries, variations in the severity of dysphasia were equally apparent, and in one case there was virtually no evidence of any disorder of this kind. Since we were concerned, among other things, to stress the liability of left-handed persons to speech disturbances even when the lesion is strictly confined to the left hemisphere, most of our available space has been given up to describing such cases. We shall, however, describe a case of right hemisphere injury in a left-hander sufficiently to indicate that a comparable language disability may be involved.

Case 6 (No. 9501).-A private, aged 21, strongly lefthanded, was wounded by a shell fragment in the right mid-parietal region in August, 1944. The wound extended to the body of the lateral ventricle, and there was a large right extradural haematoma arising from the torn posterior branch of the middle meningeal artery. Operation (Lieut. Guthkelch) was performed within 24 hours for removal of a metallic foreign body and indriven bone fragments.

On examination the principal neurological signs were left spastic hemiplegia, supranuclear paralysis of the left side of the face and tongue, and some left-sided sensory loss. There was no hemianopia. Post-traumatic amnesia extended over about five days, retrograde amnesia being only momentary. There was almost complete motor aphasia with associated dysgraphia, but oral comprehension appeared fairly good despite some tendency to perseverate in his actions.

A fortnight later he still had great difficulty in producing a complete sentence, and was frequently at a loss 
for the word he wanted. Objects were for the most part named correctly, though there were occasional failures. In addition he had considerable dyslexia, reading about $50 \%$ of words incorrectly, without any apparent insight into his errors.

A month after injury the dysphasia had improved to the extent that he now had no difficulty in sentenceconstruction, word-finding, or object-naming, but only in pronunciation. Reading, however, was still much impaired, and this defect was still in evidence three months later, when he tended to mispronounce some words and insert others which were not there, though without appreciably altering the meaning of sentences. Writing could not be tested properly owing to the hemiplegia. (The patient wrote with his left hand.) Calculation was not extensively tested, but he was distinctly slow at simple arithmetic, especially subtraction and multiplication. General memory was also affected, in addition to his specific disability in the verbal field.

On psychological examination four months after injury, he was only slightly dysphasic in ordinary conversation; reading was slow but fairly accurate. His spelling, which he claimed had been above average previously, was now very poor, and this in addition to the hemiplegia made letter-writing very troublesome. ("Raise" and "rough" correct ; "pleasant" = "plesent" ; unable to attempt "saucer", " answer" or "Wednesday ".) In arithmetic he only just succeeded with two out of three average adult problems, and was very slow on these; here also he claimed to have been good before his injury. Verbal memory tests were not very well done : he repeated seven digits forward and five backwards, but took five attempts to master the Babcock sentence, and retained only 11 items out of 20 from a story of 20 lines. Regarding general intellectual capacity, vocabulary, general information, and comprehension (Wechsler) were all above average, but his score of only $39 / 60$ on the Raven matrices suggested the possibility of some degree of intellectual deterioration at this stage. Moreover, although attention was said to be well sustained, there was a definite impairment of learning capacity on non-verbal tests. By the time of his discharge from hospital shortly afterwards he was expressing himself quite adequately, but complained that he still had difficulty with the longer words-." my tongue won't do what I want it to ".

When re-admitted in August, 1945, a year after injury, he still showed moderate spasticity of the left leg and arm, with some sensory abnormalities. In the patient's own opinion language functions, memory, and general intellectual capacity seemed to have improved almost up to his pre-traumatic level, although he admitted to some difficulty in concentration, e.g., when playing chess or writing letters. On examination, however, his speech was still slightly hesitant and calculation slow.

A second operation (Capt. Northcroft) was carried out to remove an indriven bone fragment. Degenerated cortex was found adhering to the dura.

When re-examined four months later he was able to read with normal fluency provided he took his time, and he had learnt to write quite well with his right hand, though he was still apt to make mistakes. On enquiry, he admitted that spontaneous speech still caused him a little difficulty, but it appeared almost normal except under stress. On an object-naming test he hesitated on only one out of 12 objects (wrist-watch = " winder ").

Owing to the development of post-traumatic epilepsy he was detained in hospital under observation for the greater part of the next 18 months. When finally discharged in May, 1947, he was able to resume his pre-war work (hosiery dyeing) for a short time.

Regarding handedness, there can be no question that this patient was strongly left-handed before his injury, and had always written with his left hand. Since his injury he has been able to do very little with his left hand owing to residual hemiplegia.

Case 7 (No. 8846).-On an officer, aged 32, who had been left-handed apart from writing, both the injury and the ensuing dysphasia were broadly comparable to the preceding case. Since, however, this case presented in addition to the dysphasia certain other features, notably impaired visualization and topographical loss, which were thought to have a special bearing on the problem of minor hemisphere function, it has been made the subject of a separate communication (Humphrey and Zangwill, 1952).

In our next case the outstanding feature was a permanent agraphia, other language functions being only temporarily impaired.

Case 8 (No. 9982).-A corporal, aged 26, naturally left-handed though partially ambidextrous, was wounded by a shell fragment in the right frontal lobe in September, 1944 , causing extensive destruction of brain tissue in the fronto-parietal region. Operation (Capt. Turner) was performed to remove a large, indriven bone fragment, and necrotic brain was sucked out, leaving a shallow laceration under a large dural defect. Early neurological signs included a left hemiplegia with facial paresis, sensory and Babinski loss, and left homonymous hemianopia.

When first examined he was sufficiently conscious to obey simple commands, but would not attempt to speak or answer questions. Three weeks later it was still difficult to elicit other than monosyllabic answers from him : moreover his speech was slurred, though some of his words were quite clearly enunciated. He had no apparent difficulty in naming objects. When asked to write his name he seemed quite unable to put pencil to paper, merely remarking " it might be signing my own death warrant ". In attempting to read aloud he would read several words at a burst, then miss out a number and pick up a few more later in the paragraph. He showed no sign of understanding simple written commands. A month after injury his speech functions had recovered very well, apart from writing : thus he was able to carry out complicated oral commands, could express himself well, read normally and give the 
gist of what he had just read, yet he could manage no more than an indecipherable scrawl with his right hand, though he seemed quite confident that he would be able to write his name. (It must be borne in mind, however, that the patient had always written with his left hand for preference before his injury, though he claimed to have been able to write with his right hand to a limited degree.) He also showed considerable impairment of calculation: simple feats of subtraction or multiplication were within his grasp but he failed consistently in his attempts to add double figures. He further complained of difficulty in recognizing people and in finding his bed in the ward.

Psychometric tests in December, 1944, gave evidence of marked intellectual deterioration: vocabulary, general information, and comprehension (Wechsler) were somewhat above average, corresponding to IQ 110 , but he scored under 20 on the progressive matrices, and memory and learning capacity were noticeably impaired. Spelling was about average. At the time of his discharge from hospital in May, 1945, his general condition was almost back to normal, but his ability to write with his right hand had not improved.

In May, 1946, he was re-admitted following persistent attacks of traumatic epilepsy. Meanwhile the left leg had improved immensely, but there was still severe spasticity of the left arm. There was partial improvement in the hemianopia. He stated that his powers of reading had improved tremendously, and he was now able to read a book right through. Writing, on the other hand, was very little improved. Thus an examining neurologist commented : "A very interesting case of a deep fronto-parietal injury in a left-handed man. Complete recovery of speech except for almost complete agraphia, suggesting that the 'writing centre' is in this case entirely right-sided but that the rest of his speech functions were bilaterally represented ". There was no evidence on psychometric tests of any appreciable improvement in his general intellectual level. Calculation was still definitely impaired, and there was probably some verbal memory loss; for example, he was unable completely to master the Babcock sentence in the course of 10 trials. His behaviour in the test situation was described as very " concrete" in Goldstein's sense.

More recent information indicates that the hemiplegia and intellectual loss have left him permanently disabled, as might have been expected from the severity of his injury.

The patient was naturally left-handed, but some attempt had evidently been made to teach him to write with his right hand since he claimed that he had previously been able to write with either hand, though normally preferring his left for this and most other purposes.

The two remaining cases of right hemisphere injury deserve brief mention.

Case 9 (No. 9054).-A private, aged 31, who was wounded by a shell fragment high up in the posterior frontal region, never gave any definite clinical evidence of true dysphasia, but about six months after injury an examining psychologist found, on the evidence of selected verbal tests, a slight residual impairment of language in both its expressive and receptive aspects. Spelling was also affected. He made a good general recovery, yet even as long as two years after injury, when he was admitted for skull repair, an examining neurologist commented, "I think there is a minimal nominal dysphasia and slight dysarthria ". The patient also complained of frequent memory lapses. Before his injury he had been left-handed for most purposes other than writing, but subsequently he found great difficulty in adapting to the change-over that was forced upon him by the sensory loss in his left hand.

Case 10 (No. 10880).-A lance-corporal, aged 31, naturally left-handed but a right-handed writer, sustained a severe injury of the right mid-parietal region, causing left hemiplegia, cortical sensory loss, and slight slurring of motor speech but no true dysphasia. (Indeed, he remembered being able to speak immediately after injury.) There was no appreciable intellectual loss.

(A similar case of severe right hemisphere injury producing no obvious language disability in a patient who was entirely left-handed has since come to our notice.)

\section{Analysis of Case Material}

Site of Injury.-The anatomical distribution of left and right hemisphere injuries in terms of areas of the cerebral cortex is shown in Table I.

TABLE I

SITE OF WOUNDING IN THE CASES STUDIED

\begin{tabular}{lll|c|c}
\hline \multicolumn{2}{c|}{ Site of Wound } & Left Hemisphere & Right Hemisphere \\
\hline Parietal . & $\ldots$ & $\ldots$ & 1 & 2 \\
Posterior parietal & & $\ldots$ & 1 & 1 \\
Fronto-parietal & $\ldots$ & $\ldots$ & 1 & 2 \\
Temporal .. & $\ldots$ & $\ldots$ & 1 & - \\
Fronto-temporal & $\ldots$ & $\ldots$ & 1 & - \\
\hline
\end{tabular}

Handedness.-All patients had regarded themselves as predominantly left-handed before their injury. Three patients in either group had been taught to write with the right hand, while the other two had written with the left hand up to the time of injury. Further, at least two cases of left hemisphere injury and at least one (possibly two) of right hemisphere injury had shown ambidextrous tendencies. One may suggest that the latter were certainly present to a limited degree in all cases of left hemisphere injury, but more doubtfully so in the right hemisphere group. Residual physical disabilities resulting from the injury compelled an almost complete change of handedness in all the right hemisphere cases, although only two patients (Cases 6 and 8) had to change their writing hand. A peculiar difficulty in adapting himself to the change of handedness was reported by only one 
patient (Case 9), although no doubt this was experienced to some extent in all cases; one previously left-handed writer (Case 6) learnt successfully to write with his right hand in the year following his injury.

Language Disorders.-The distribution of language disorders in the two groups (left and right hemisphere injuries) is given in Table II.

TABLE II

DISTRIBUTION OF LANGUAGE DISORDERS IN THE CASES STUDIED

\begin{tabular}{|c|c|c|c|c|c|c|c|c|c|c|}
\hline \multirow[b]{2}{*}{ Case No. } & \multicolumn{5}{|c|}{$\begin{array}{l}\text { Left Hemisphere } \\
\text { Injuries }\end{array}$} & \multicolumn{5}{|c|}{$\begin{array}{l}\text { Right Hemisphere } \\
\text { Injuries }\end{array}$} \\
\hline & 1 & 2 & 3 & 4 & 5 & 6 & 7 & 8 & 9 & 10 \\
\hline 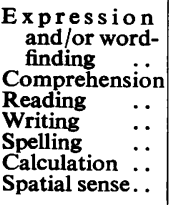 & $\begin{array}{l}+ \\
+ \\
+ \\
+ \\
+ \\
+ \\
+\end{array}$ & $\begin{array}{c}+ \\
+ \\
(+) \\
+ \\
\frac{+}{-}\end{array}$ & $\begin{array}{c}+ \\
+ \\
(+) \\
+ \\
+ \\
? \\
-\end{array}$ & $\begin{array}{l}+ \\
+ \\
+ \\
? \\
+ \\
- \\
-\end{array}$ & $\begin{array}{l}+ \\
+ \\
+ \\
+ \\
? \\
-\end{array}$ & $\begin{array}{l}+ \\
\dot{+} \\
? \\
+ \\
+ \\
+\end{array}$ & $\begin{array}{l}+ \\
+ \\
+ \\
+ \\
\dot{+} \\
+ \\
+\end{array}$ & $\begin{array}{l}+ \\
+ \\
+ \\
+ \\
+ \\
+ \\
+\end{array}$ & $\begin{array}{l}+ \\
? \\
- \\
+ \\
+ \\
+\end{array}$ & $\begin{array}{l}\bar{z} \\
\overline{-} \\
\bar{z} \\
\overline{-}\end{array}$ \\
\hline
\end{tabular}

Plus sign $=$ impaired $;$ minus sign $=$ no evidence of impairment ; $(+)=$ probable slight impairment.

Owing to the varying intervals between successive examinations, the fact that the cases were seen by different examiners at different stages, the difficulties which, in any case, would be involved in trying to determine at all accurately the degree of impairment, and in deciding whether such impairment is to be regarded as permanent, no attempt has been made to differentiate in Table II between mild and severe, or transitory and permanent, grades of defect. Broadly speaking, however, it may be noted that in the left hemisphere group recovery of language functions after periods varying from six months to two years was practically complete in Case 2 , very satisfactory in Cases 3 to 5 , and extremely limited in Case 1 (a very severe injury, involving gross loss of brain substance). Speech therapy was given in Cases 1 , 2 , and 4. In the right hemisphere group, language recovery was complete in Case 7 with the help of speech therapy, and very satisfactory in Case 6 ; in Case 8 writing was the only language function permanently impaired; in Case 9 the degree of original impairment was relatively slight, while in Case 10 language was never affected apart from a mild slurring of motor speech. On the other hand calculation was permanently impaired in all the right hemisphere injuries except Case 10. Disturbances of spatial sense were confined to two cases in this group. Residual dysphasia in almost all cases of both groups took the form of a slight hesitancy of speech and difficulty in word-finding.

The relative incidence of the various defects is illustrated numerically in Table III.

TABLE III

RELATIVE INCIDENCE OF DEFECTS IN CASES STUDIED

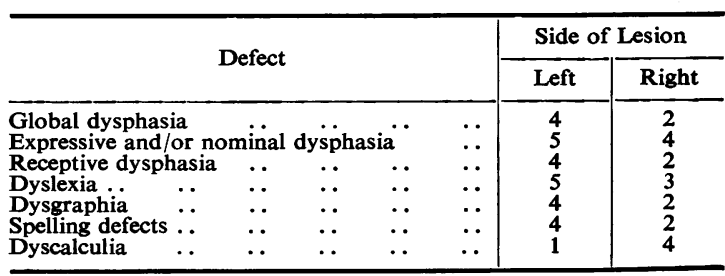

Thus if we exclude dyscalculia, which apart from the one case of severe and permanent dysphasia, where the lesion was left-sided, was confined to the right-sided cases, the incidence of dysphasic and other symptoms is consistently higher in the left hemisphere group.

General Intellectual Capacity.-There is good evidence that Cases 2 and 3 of the left hemisphere, and Case 7 of the right hemisphere, injuries were men of superior intelligence, as judged by personal history and performance on the Wechsler tests of vocabulary, general information, and comprehension. The remainder were probably all of at least average intelligence and in some cases a little above average. The balance between the two groups is approximately even in this respect. Varying degrees of general intellectual deterioration, as measured by tests of sorting and of reasoning by analogy, were demonstrated in three cases of left hemisphere injury (Nos. 1, 3, and 4) and in all the right hemisphere injuries with the exception of Case 10. This deterioration was severe and caused permanent incapacity in Cases 1 and 8 (both very extensive lesions, left- and right-sided respectively), milder and with less harmful consequences in the remaining cases. A specific memory defect, as distinct from severe loss of general intellectual capacity, was conspicuous in Cases 3 and 9, left- and right-sided injuries respectively.

Physical Signs.-Hemiplegia was severe and residual in Cases 2 and 5 of the left hemisphere injuries, and in all the right hemisphere injuries except Case 9, where it was mild and transitory. A lesser degree of early hemiplegia was also shown by Cases 1 and 4, but there was none in Case 3 (left hemisphere injuries). Varying degrees of cortical sensory loss were demonstrated in all cases 
of right hemisphere injury, but only in Case 2 of the left hemisphere injuries. Hemianopia was present in Cases 1, 7, and 8. Apart from the above disabilities, a good physical recovery was achieved in all cases.

\section{Discussion}

The fact which emerges most clearly from this study of the effects of unilateral brain lesions in left-handed patients is that some evidence of "language disorder", this broad term being intended to cover disturbances of reading, writing, spelling, calculation, and verbal memory or learning, in addition to dysphasia in the narrower sense, was found in one form or another in all cases except one, irrespective of the laterality of the lesion. It is true that one of the criteria determining the selection of our cases was that " the lesion must be such as would be expected to interfere with speech functions if the affected hemisphere were the dominant one"; yet if left-handedness were correlated with "right-brainedness" to the same degree as right-handedness with " left-brainedness," as has commonly been assumed, then dysphasia would have been expected to occur only in the right hemisphere injuries. Our findings go even further against the traditional view in that the various forms of language disorder, with the exception of dyscalculia, show a higher incidence in the cases of left hemisphere injury.

In drawing attention to this apparent anomaly we cannot claim to have made an entirely new discovery. In the nine cases reported by Chesher (1936) of persons with mixed handedness, the lesions giving rise to dysphasia were again almost equally divided between the left and right hemispheres, while the same lack of uniformity regarding cerebral dominance has been observed by Conrad (1949) and by Penfield and Rasmussen (1950) even in persons who were not noted for any mixture of handedness. It would appear, however, that the mere fact of writing with the right hand, in a person who is strongly left-handed for most other purposes, is regarded by some writers as an example of mixed handedness. In some of the cases studied by the other authors quoted here handedness may have been " mixed" in this sense. Moreover, the same slight, and not necessarily significant, preponderance of left hemisphere lesions was observed by Conrad in his series of left-handed aphasics. Yet no detailed account of dysphasic manifestations in their cases is offered by any of the above-mentioned authors, and so far as we are aware none of the more elaborate studies of aphasia so far published have been brought into relation with problems of handedness. On such grounds alone it is hoped that our own detailed presentation will prove justified.

The fact that only one of our carefully selected cases was free from dysphasic symptoms lends further support to the hypothesis put forward by previous writers that cerebral dominance either does not occur at all in the so-called left-handed, or if it does occur, tends to be less well developed than in the general run of right-handed persons. It is true that no detailed study of right-handed aphasics has been included here; yet in support of our contention the following facts may be adduced. Of 492 cases of penetrating brain injuries studied from the point of view of handedness, site of lesion and presence or absence of dysphasia, 436 were known to be right-handed ; of these 105 were still dysphasic at the time of their discharge from hospital, yet the lesion was with one single exception confined to the left hemisphere. Thus it would be impossible to select from this group of right-handed aphasics 10 cases showing a comparable division between left- and right-sided lesions, while it is extremely unlikely that, if 10 cases were selected at random from the total right-handed group of 436 cases, only one would be free from dysphasia.

In regard to individual differences of handedness in our 10 cases, the available information was too limited for us to apply the method of assessment and classification put forward by one of us elsewhere (Humphrey, 1951). Broadly speaking, however, our patients were all primarily left-handed, though some were partially ambidextrous. It is thus remarkable that only two cases, left-handed and right-handed writers respectively, showed an appreciable degree of " right-brainedness" so far as spoken language was concerned; in one other case there was good evidence of left-handed writing being predominantly governed by the right hemisphere, according to expectation, yet the remaining seven cases showed a marked tendency toward "left-brainedness" in all their speech functions.

The fact that only three of our patients were under 30 at the time of injury, all being left-handed writers, is of considerable importance in the present context. Of the rest only one had remained a left-handed writer, the others having been com-. pulsorily shifted at an early age ; in two of the left-handed writers also there was some history of early interference with writing habits. If we take into account the conclusion reached by Humphrey (1951) that the early conversion of a naturally lefthanded individual to right-handed writing is liable to influence his later manual habits not only in regard to writing itself, but also secondarily in 
promoting a greater tendency toward ambidexterity and a more frequent preference for the right hand in situations favouring its use, then it seems reasonable to assume that a corresponding influence is likely to be exerted on such an individual's ultimate cerebral organization. If this is the case, then we should also draw attention to the fact that most of the patients included in the present study were born at a time when social pressure against lefthandedness in general, and left-handed writing in particular, was still fairly strong. Now that the pendulum has swung the other way, and children are in many cases even actively encouraged to write with the left hand if so inclined, it is theoretically possible that "right-brainedness" will gradually gain in both strength and frequency among the naturally left-handed.

One final point merits brief discussion. It has already been suggested that cerebral dominance may be relatively undeveloped in many left-handed persons. This would in turn imply that cerebral representation of the language functions in such cases is bilateral, at any rate to a greater degree than in most right-handed people (Chesher, 1936). From this it would follow that handedness was a possible or even an important factor in speed of recovery from dysphasia, since the other, uninjured hemisphere would in these circumstances be far more ready to take over full control of the speech functions when called upon to do so. Unfortunately our material does not throw any further light on this question. It is true that our left-handed patients achieved an excellent recovery of language, except in those two cases where the injury was exceptionally severe; yet this has no final significance without a control group of right-handed aphasics with broadly comparable lesions. While it would be easy enough to assemble such a group of cases, the assessment of comparative rates of recovery through the study of case histories would be a far more problematic undertaking. Careful study and psychological assessment of aphasic patients personally and over a long period, coupled with a full investigation of their handedness and other aspects of laterality (Humphrey, 1951), will be necessary if this tentative conclusion is to be tested as systematically as it deserves; while at the same time we must realize that the problem of recovery from aphasia cannot be approached from the neurophysiological viewpoint alone, since various other factors, including above all the personality of the patient, are undoubtedly involved. By drawing attention to this apparent peculiarity in the cerebral organization that is associated with left-handedness we may hope to stimulate further research along these lines, while at the same time stressing the importance of obtaining accurate information as to handedness in the course of routine neurological examination of patients with brain injury.

\section{Summary}

Ten carefully selected cases of unilateral brain lesion (five left-sided and five right-sided) in naturally left-handed patients of good intelligence were studied with reference to the cerebral representation of language functions.

Dysphasia was present in all cases of left hemisphere lesion and in all but one of the right hemisphere cases. On balance the dysphasic symptoms were more severe in the former group, although defects of calculation were more prominent in the latter.

Some theoretical implications in regard to handedness and cerebral dominance are discussed.

We wish to thank Dr. W. Ritchie Russell for his generous encouragement and kind permission to quote extracts from the case records of the Head Injury Advice Bureau, and to interview patients under his care.

\section{REFERENCES}

Bastian, H. C. (1898). Aphasia and Other Speech Defects. London.

Brain, W. Russell (1945). Lancet, 2, 837.

Bramwell, B. (1899). Ibid., 1, 1473 .

Chesher, E. C. (1936). Bull. neurol. Inst. N.Y., 4, 556.

Conrad, K. (1949). Nervenarzt, 20, 148.

Head, H. (1926). Aphasia and Kindred Disorders of Speech. Cambridge.

Humphrey, M. E. (1951). Brit. J. educ. Psychol., 21, 214. -, and Zangwill, O. L. (1952). Brain. To be published.

Jackson, J. Hughlings (1879). Brain, 1, 304. Reprinted in Brain, 1915, 38, 107.

Macnaughton-Jones, H. (1914). Ambidexterity and Mental Culture. London.

Needles, W. (1942). J. nerv. ment. Dis., 95, 270.

Penfield, W., and Rasmussen, T. (1950). The Cerebral Cortex of Man. New York.

Tilney, F. (1936). Arch. Neurol. Psychiat., Chicago, 36, 897.

Weisenburg, T., and McBride, K. E. (1935). Aphasia, a Clinical and Psychological Study. New York.

Wile, I. S. (1934). Handedness : Right and Left. Boston. 